\title{
The nucleoid as a site of rRNA processing and ribosome assembly
}

\author{
Alexandra-Viola Bohne* \\ Department of Molecular Plant Sciences, Ludwig-Maximilians-University Munich, Planegg-Martinsried, Germany \\ ${ }^{*}$ Correspondence: alexandra.bohne@Imu.de \\ Edited by: \\ Thomas Pfannschmidt, University Joseph Fourier Grenoble, France \\ Reviewed by: \\ Alice Barkan, University of Oregon, USA \\ Katharine A. Howell, The University of Western Australia, Australia
}

Keywords: rRNA processing, ribosome assembly, nucleoid, plastid, mitochondria

Protein biosynthesis is one of the key elements of gene expression in living cells. All proteins are synthesized on ribonucleoprotein complexes, the ribosomes. In bacteria and their derivativeseukaryotic mitochondria and plastidsribosomes consist of a small and a large subunit which together comprise more than 50 ribosomal proteins and usually two to four ribosomal RNAs (rRNAs). Synthesis of the required rRNAs and proteins, and their correct folding, maturation/modification and assembly into functional particles are highly coordinated. However, whereas ribosomal composition and many mechanistic aspects of their biogenesis are well understood, little is known about the spatial organization of the procedure in bacteria and organelles. In eukaryotes, the individual processes involved occur in defined regions of the cell: ribosomal proteins are synthesized in the cytosol, but most rRNAs are transcribed, processed and modified in the nucleolus, a distinct subnuclear compartment (Lafontaine and Tollervey, 2001; Boisvert et al., 2007). Only the transcription of the small $5 S$ rRNA occurs in the nucleoplasm. After their synthesis, ribosomal proteins and assembly factors are imported into the nucleus, where they are combined with the appropriate rRNAs. Subsequently, small and large ribosomal subunits are exported into the cytosol, where they pair up to form functional ribosomes.

This Opinion Article focuses on recent findings which support the idea that, as in eukaryotes, ribosomal biogenesis in bacteria, mitochondria, and plastids is spatially organized. In these systems, there is growing evidence that rRNA processing and ribosome assembly most likely take place in association with the nucleoid.

\section{rRNA PROCESSING, MATURATION AND RIBOSOME ASSEMBLY IN BACTERIA}

The processes of rRNA maturation and ribosome assembly are probably best understood in bacteria (reviewed in Kaczanowska and Rydén-Aulin, 2007; Shajani et al., 2011). In E. coli, the small $30 S$ ribosomal subunit contains 21 ribosomal proteins and a $16 S$ rRNA, while the large $50 S$ subunit consists of 33 proteins and two rRNAs, the $23 S$ and $5 S$ rRNAs (reviewed in Melnikov et al., 2012). All rRNAs are encoded in a polycistronic gene cluster and transcribed as a single precursor, which undergoes extensive processing and maturation to generate the mature rRNAs (reviewed in Deutscher, 2009; Shajani et al., 2011). The processing reactions are carried out by the exoor endonucleolytic activities of at least five ribonucleases (RNases), including RNases III, E, G, T, and YbeY (reviewed in Deutscher, 2009; Davies et al., 2010). Furthermore, the $23 \mathrm{~S}$ and $16 \mathrm{~S}$ rRNAs undergo methylations and pseudouridylations at several positions, which are assumed to influence ribosomal structure and function (reviewed in Shajani et al., 2011).

Many of these maturation steps are coupled and take place on nascent rRNAs. The final rRNA folding pattern is probably determined by an ordered sequence of interactions with ribosomal proteins and assembly factors, which induce conformational changes and stabilize the proper
rRNA structures (reviewed in Shajani et al., 2011).

It was long believed that DNAassociated bacterial ribosomes translate nascent mRNAs while these are being synthesized by the RNA polymerase (co-transcriptional translation). Striking evidence for this hypothesis came from early electron microscopy studies showing ribosome arrays (polysomes) attached to mRNA strands that were being transcribed from DNA by multiple RNA polymerase (RNAP) molecules (Miller et al., 1970). However, recent research suggests that, at least in E. coli and B. subtilis, most translation is not coupled to transcription, and that cotranscriptional translation may be limited to mRNAs encoding membrane proteins. By tracking the distribution of RNA polymerases (as markers for the nucleoid DNA) and ribosomes by means of fluorescence microscopy, a clear segregation of the nucleoid from ribosome-rich regions of the cytoplasm was observed (Lewis et al., 2000; Bakshi et al., 2012; Chai et al., 2014). Bakshi et al. (2012) found approximately $85 \%$ of the ribosomes in the ribosome-rich regions, while only 10 to $15 \%$ were detected in close proximity to the nucleoid. The majority fraction probably comprises actively translating "protein factories." The nucleoid-associated particles are thought to be in various stages of assembly, as several rRNA maturation steps occur in a cotranscriptional and assembly-assisted manner (reviewed in Shajani et al., 2011).

Further data support the identification of the nucleoid as the site of early rRNA processing events. RNase III, which cotranscriptionally cleaves the primary 
rRNA transcript to yield $16 S, 23 S$, and $5 S$ precursors, has been shown to be required for localization of the pre-16S rRNA $5^{\prime}$ leader region to the nucleoid (Malagon, 2013). In RNA-FISH assays for single-cell visualization, Malagon (2013) found that the nucleoid localization of the $16 S 5^{\prime}$ leader was dependent on the catalytic activity of RNase III, which provides indirect evidence for the presence of the enzyme in this region. Based on evidence for interplay between the Nus transcription elongation factors and RNase III in the modulation of pre-rRNA biogenesis (Bubunenko et al., 2013), Malagon further speculated that Nus proteins might serve to localize pre-rRNAs to the nucleoid.

\section{LOCALIZED rRNA PROCESSING AND RIBOSOME ASSEMBLY IN ORGANELLES}

Eukaryotic plastids and mitochondria are descended from endosymbiotically acquired bacteria, and have retained their own genomes and machineries for gene expression during evolution. It is therefore not surprising that many aspects of these genetic systems, including genome organization and ribosome structure, resemble those of bacterial rather than eukaryotic systems. Similarly, evidence for sublocalization of rRNA processing and ribosome assembly events to the organellar nucleoids is now emerging.

\section{MITOCHONDRIA}

Evidence for rRNA maturation and ribosome assembly in association with the mitochondrial nucleoid mainly derives from studies on mammalian mitochondria. Affinity purification of established protein components of the mitochondrial nucleoid results in copurification of ribosomal proteins and the ribosome assembly factor ERAL1 (He et al., 2012b). ERAL1, a GTP-binding protein with RNA-binding activity, which had previously been linked with a number of nucleoid proteins, interacts both with proteins of the small mitoribosomal subunit and its rRNA component (Dennerlein et al., 2010; Uchiumi et al., 2010). ERAL1 was proposed to act as a chaperone for the small ribosomal RNA, as its depletion leads to destabilization of the small subunit (Dennerlein et al., 2010).

Similarly, another mitoribosome assembly factor, the human GTPase NOA1
(C4orf14), a homolog of the plant Rif1 protein, has been found together with the small ribosomal subunit and translation factors in affinity-purified nucleoids (Flores-Pérez et al., 2008; He et al., 2012a). This finding prompted the suggestion that assembly of the small subunit in the mitochondrial nucleoid enables the direct transfer of newly transcribed mRNAs to the ribosome.

Like bacterial rRNAs, mammalian mitochondrial rRNAs undergo sitespecific methylations, although to a lesser extent (reviewed in Rorbach and Minczuk, 2012). The enzymes responsible belong to a family of rRNA methyltransferases, some of whose members have been reported to modify nascent rRNAs in association with the nucleoid (Lee et al., 2013). A more detailed analysis of one of these methyltransferases (named RNMTL1) revealed an additional interaction between this protein and the large ribosomal subunit, suggesting that assembly of mitochondrial ribosomes begins before rRNA transcription is complete (Lee et al., 2013).

Moreover, a very recent study by Bogenhagen et al. (2014) provides evidence that mammalian mitochondrial RNA processing enzymes, like RNase $\mathrm{P}$ and ELAC2 (tRNase $Z_{\mathrm{L}}$ ), as well as a number of nascent mitochondrial ribosomal proteins associate with nucleoids to initiate RNA processing and ribosome assembly. The authors therefore propose the mtDNA nucleoid as a critical control center for mitochondrial biogenesis.

\section{PLASTIDS}

An extensive body of evidence for localized ribosome biogenesis comes from plastids. Besides numerous ribosomal proteins, the majority of proteins with known roles in ribosome biogenesis have been identified in a comprehensive proteomic analysis of the maize chloroplast nucleoid (Majeran et al., 2012; reviewed in Germain et al., 2013). Many of these nucleoid-enriched ribosome biogenesis factors function in rRNA processing, maturation and modification, as well as in ribosome assembly (summarized in Table $\mathbf{1}$ ).

Among the processing and splicing factors identified are many plant homologs of bacterial RNases that have been reported to be responsible for exo- and endonucleolytic cleavage of the large rRNA precursor and maturation of cotranscribed tRNAs (reviewed in Stoppel and Meurer, 2012; Germain et al., 2013). Most of the nucleoid-enriched proteins involved in ribosome assembly and rRNA modification are classified as either GTPases, RNA helicases or rRNA methylases (Table 1).

Two of the nucleoid-enriched plastid proteins listed in Table $\mathbf{1}$ are homologous to the mitochondrial enzymes ERAL1 and NOA1, for which a nucleoid localization has also been reported (see above). For several others, links with the nucleoid are further supported by alternative approaches as exemplified in the following.

An immunological analysis of maize chloroplast subfractions revealed that the DEAD-box RNA helicase RH3, thought to function in assembly of the $50 S$ subunit, localizes to the chloroplast stroma and thylakoids, as well as to nucleoids (Asakura et al., 2012). For two recently characterized plant proteins required for ribosome biogenesis, DER and RAP, cytological evidence for nucleoid localization comes from GFP fusion experiments (Jeon et al., 2014; Kleinknecht et al., 2014). DER is a Double Era-like GTPase, whose bacterial homolog (also known as EngA) acts as a ribosome assembly factor in E. coli, was found to bind to the $50 S$ ribosomal subunit and to play a role in pre-rRNA processing in tobacco (Hwang and Inouye, 2006; Jeon et al., 2014). The Arabidopsis protein RAP is a member of the Octotricopeptide Repeat (OPR) protein family, and binds to the $5^{\prime}$ leader sequence of the $16 \mathrm{~S}$ rRNA precursor (Kleinknecht et al., 2014). Depletion of RAP specifically affected the trimming/processing of the chloroplast $16 \mathrm{~S}$ rRNA precursor, which supports the identification of the nucleoid as the site of $16 S$ rRNA processing in chloroplasts. Preliminary data imply that RAP has no intrinsic RNase activity, and might influence $16 S$ rRNA maturation by conferring sequence specificity on an RNase or by modulating RNA secondary structures to control the accessibility of an RNase recognition site within the $16 S$ precursor (Kleinknecht et al., unpublished results).

However, in the case of many chloroplast proteins reported to be involved in various steps of ribosome biogenesis, GFP-based fusion studies provide no 
Table 1 | Nucleoid-localized proteins with proposed functions in rRNA processing, maturation and ribosome assembly in plant chloroplasts.

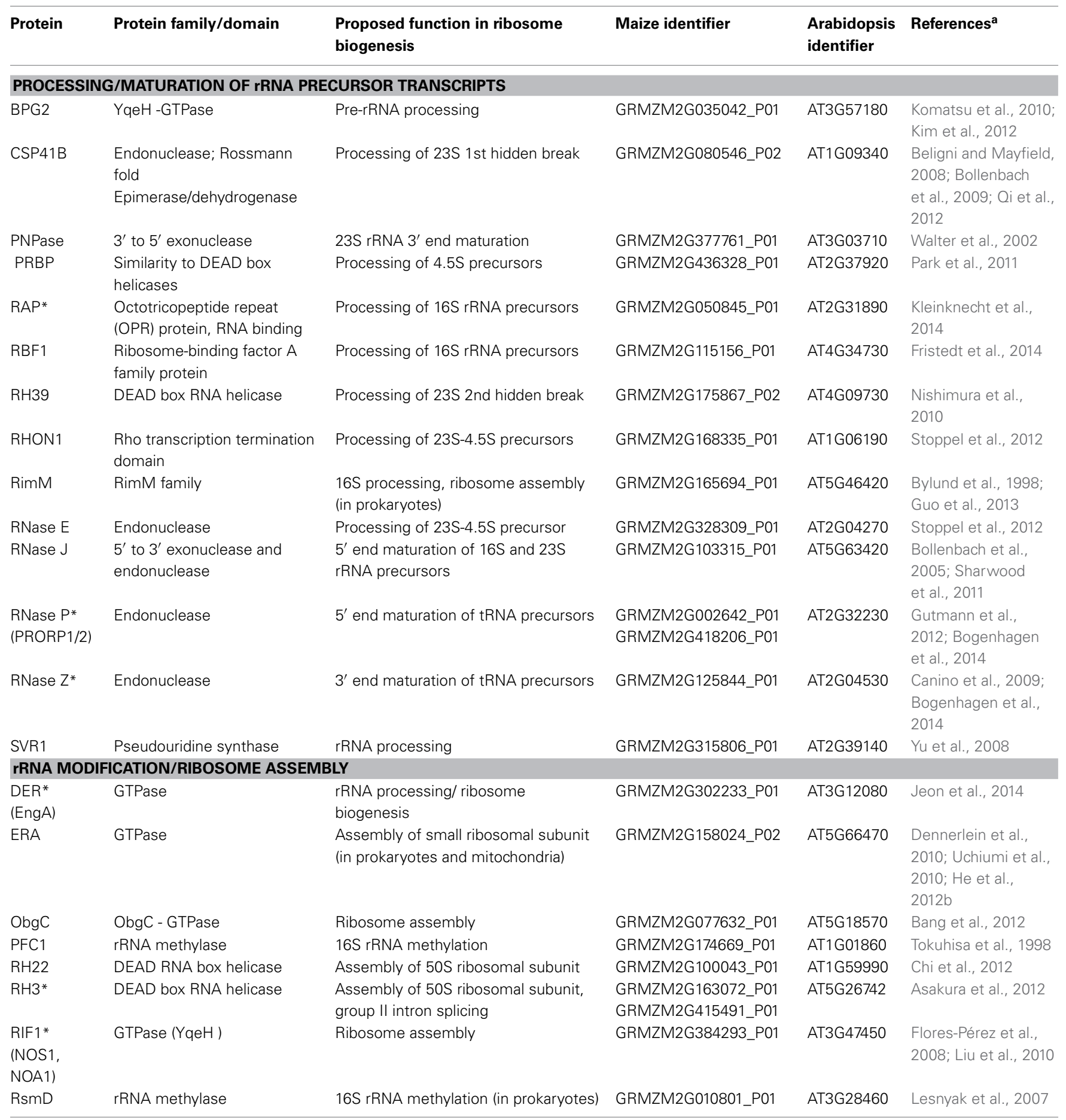

All proteins listed were identified as nucleoid proteins by Majeran et al. (2012). Proteins known to be involved in ribosome biogenesis but not identified in their nucleoid fraction, as well as factors that probably have only indirect effects on rRNA maturation and ribosome assembly, are not included in this list.

${ }^{*}$ Nucleoid localization demonstrated by groups other than (Majeran et al., 2012) (see text).

${ }^{a}$ Only most relevant publications referring to a function in ribosome biogenesis or nucleoid localization are listed.

support for specific localization to the plastid nucleoid. One possible reason for this may be the use of transit peptide-GFP instead of full-length protein fusions, as determinants of nucleoid localization are unlikely to be encoded in the transit peptide. Accordingly, Park et al. (2011) also reported the localization of the protein PRBP, which likely functions in $4.5 \mathrm{~S}$ rRNA processing, to distinct spots within chloroplasts, which probably represent nucleoids. This sublocalization 
was only observed when the full-length protein was fused to GFP and not with a transit peptide-GFP fusion. Nevertheless, other proteins for which full length-GFP fusions were used could not be clearly assigned to the nucleoid (e.g., Flores-Pérez et al., 2008; Yu et al., 2008; Chi et al., 2012). This might be due to weak or transient association of the respective protein with the nucleoid. Alternatively, some of these proteins may perform further functions in other organellar subcompartments leading to ambiguous localization signals.

\section{CONCLUSION AND FUTURE PERSPECTIVES}

Localization of rRNA processing and ribosome assembly to organellar nucleoids seems to be a general phenomenon derived from a bacterial ancestor. Unlike the case of the eukaryotic nucleus, no physical barrier intervenes between bacterial/organellar RNA synthesis and translation. The nucleoid might therefore provide a scaffold for an intra-organellar microenvironment which enables coupling of rRNA transcription to ribosome assembly. This might not only enhance the efficiency of ribosome assembly by substrate channeling, but also largely prevent the precocious association of mRNAs with immature $30 S$ ribosomal subunits. However, it remains to be shown whether the colocalization of rRNA processing and ribosome assembly with nucleoids has functional significance or simply reflects the rapid kinetics with which ribosome biogenesis factors bind to nascent rRNA targets.

Nonetheless, the growing awareness of the requirement for sublocalized cellular processes in apparently less organized bacteria and organelles, and the availability of more sensitive detection techniques including super-resolution imaging, will undoubtedly lead to new insights into the spatiotemporal organization of ribosome biogenesis in the future.

\section{ACKNOWLEDGEMENT}

I thank Joerg Nickelsen for critical reading of this article.

\section{REFERENCES}

Asakura, Y., Galarneau, E., Watkins, K. P., Barkan, A., and van Wijk, K. J. (2012). Chloroplast RH3 DEAD Box RNA helicases in maize and Arabidopsis function in splicing of specific group II introns and affect chloroplast ribosome biogenesis. Plant Physiol. 159, 961-974. doi: 10.1104/pp.112.197525 Bakshi, S., Siryaporn, A., Goulian, M., and Weisshaar, J. C. (2012). Superresolution imaging of ribosomes and RNA polymerase in live Escherichia coli cells. Mol. Microbiol. 85, 21-38. doi: 10.1111/j.13652958.2012.08081.x

Bang, W. Y., Chen, J., Jeong, I. S., Kim, S. W., Kim, C. W., Jung, H. S., et al. (2012). Functional characterization of $\mathrm{ObgC}$ in ribosome biogenesis during chloroplast development. Plant J. 71, 122-134. doi: 10.1111/j.1365-313X.2012.04976.x

Beligni, M., and Mayfield, S. (2008). Arabidopsis thaliana mutants reveal a role for CSP4la and CSP41b, two ribosome-associated endonucleases, in chloroplast ribosomal RNA metabolism. Plant Mol. Biol. 67, 389-401. doi: 10.1007/s11103-0089328-2

Bogenhagen, D. F., Martin, D. W., and Koller, A. (2014). Initial steps in RNA processing and ribosome assembly occur at mitochondrial DNA nucleoids. Cell Metab. 19, 618-629. doi: 10.1016/j.cmet.2014.03.013

Boisvert, F.-M., van Koningsbruggen, S., Navascues, J., and Lamond, A. I. (2007). The multifunctional nucleolus. Nat. Rev. Mol. Cell Biol. 8, 574-585. doi: $10.1038 / \mathrm{nrm} 2184$

Bollenbach, T. J., Lange, H., Gutierrez, R., Erhardt, M., Stern, D. B., and Gagliardi, D. (2005). RNR1, a $3^{\prime}-5^{\prime}$ exoribonuclease belonging to the RNR superfamily, catalyzes $3^{\prime}$ maturation of chloroplast ribosomal RNAs in Arabidopsis thaliana. Nucleic Acids Res. 33, 2751-2763. doi: 10.1093/nar/gki576

Bollenbach, T. J., Sharwood, R. E., Gutierrez, R., Lerbs-Mache, S., and Stern, D. B. (2009). The RNA-binding proteins CSP4la and CSP41b may regulate transcription and translation of chloroplast-encoded RNAs in Arabidopsis. Plant Mol. Biol. 69, 541-552. doi: 10.1007/s11103-0089436-Z

Bubunenko, M., Court, D. L., Al Refaii, A., Saxena, S., Korepanov, A., Friedman, D. I., et al. (2013). Nus transcription elongation factors and RNase III modulate small ribosome subunit biogenesis in Escherichia coli. Mol. Microbiol. 87, 382-393. doi: 10.1111/mmi.12105

Bylund, G. O., Wipemo, L. C., Lundberg, L. A. C. and Wikström, P. M. (1998). RimM and RbfA are essential for efficient processing of 16S rRNA in Escherichia coli. J. Bacteriol. 180, 73-82.

Canino, G., Bocian, E., Barbezier, N., Echeverría, M., Forner, J., Binder, S., et al. (2009). Arabidopsis encodes four tRNase Z enzymes. Plant Physiol. 150, 1494-1502. doi: 10.1104/pp.109.137950

Chai, Q., Singh, B., Peisker, K., Metzendorf, N., Ge, X., Dasgupta, S., et al. (2014). Organization of ribosomes and nucleoids in Escherichia coli cells during growth and in quiescence. J. Biol. Chem. 289, 11342-11352. doi: 10.1074/jbc.M114.557348

Chi, W., He, B., Mao, J., Li, Q., Ma, J., Ji, D., et al. (2012). The function of RH22, a DEAD RNA helicase, in the biogenesis of the $50 S$ ribosomal subunits of Arabidopsis chloroplasts. Plant Physiol. 158, 693-707. doi: 10.1104/pp.111.186775

Davies, B. W., Köhrer, C., Jacob, A. I., Simmons, L. A., Zhu, J., Aleman, L. M., et al., (2010). Role of Escherichia coli YbeY, a highly conserved protein, in rRNA processing. Mol. Microbiol. 78, 506-518. doi: 10.1111/j.1365-2958.2010.07351.x
Dennerlein, S., Rozanska, A., Wydro, M., Chrzanowska-Lightowlers, Z. M. A., and Lightowlers, R. N. (2010). Human ERAL1 is a mitochondrial RNA chaperone involved in the assembly of the $28 \mathrm{~S}$ small mitochondrial ribosomal subunit. Biochem. J. 430, 551-558. doi: 10.1042/BJ20100757

Deutscher, M. P. (2009). Maturation and degradation of ribosomal RNA in bacteria. Prog. Mol. Biol. Transl. Sci. 85, 369-391. doi: 10.1016/S0079-6603 (08)00809-X

Flores-Pérez, U., Sauret-Güeto, S., Gas, E., Jarvis, P., and Rodríguez-Concepción, M. (2008). A mutant impaired in the production of plastomeencoded proteins uncovers a mechanism for the homeostasis of isoprenoid biosynthetic enzymes in Arabidopsis plastids. Plant Cell Online 20, 1303-1315. doi: 10.1105/tpc.108.058768

Fristedt, R., Scharff, L. B., Clarke, C. A., Wang, Q., Lin, C., Merchant, S. S., et al. (2014). RBF1, a plant homolog of the bacterial ribosome-binding factor RbfA, acts in processing of the chloroplast $16 \mathrm{~S}$ ribosomal RNA. Plant Physiol. 164, 201-215. doi: 10.1104/pp.113.228338

Germain, A., Hotto, A. M., Barkan, A., and Stern, D. B. (2013). RNA processing and decay in plastids. Wiley Interdiscip. Rev. RNA 4, 295-316. doi: 10.1002/wrna.1161

Guo, Q., Goto, S., Chen, Y., Feng, B., Xu, Y., Muto, A., et al. (2013). Dissecting the in vivo assembly of the $30 \mathrm{~S}$ ribosomal subunit reveals the role of RimM and general features of the assembly process. Nucleic Acids Res. 41, 2609-2620. doi: 10.1093/nar/gks1256

Gutmann, B., Gobert, A., and Giege, P. (2012). PRORP proteins support RNase $\mathrm{P}$ activity in both organelles and the nucleus in Arabidopsis. Genes Dev. 26, 1022-1027. doi: 10.1101/gad. 189514.112

He, J., Cooper, H. M., Reyes, A., Di Re, M., Kazak, L., Wood, S. R., et al. (2012a). Human C4orf14 interacts with the mitochondrial nucleoid and is involved in the biogenesis of the small mitochondrial ribosomal subunit. Nucleic Acids Res. 40, 6097-6108. doi: 10.1093/nar/gks257

He, J., Cooper, H. M., Reyes, A., Di Re, M., Sembongi, H., Litwin, T. R., et al. (2012b). Mitochondrial nucleoid interacting proteins support mitochondrial protein synthesis. Nucleic Acids Res. 40, 6109-6121. doi: 10.1093/nar/gks266

Hwang, J., and Inouye, M. (2006). The tandem GTPase, Der, is essential for the biogenesis of $50 \mathrm{~S}$ ribosomal subunits in Escherichia coli. Mol. Microbiol. 61, 1660-1672. doi: 10.1111/j.13652958.2006.05348.x

Jeon, Y., Ahn, C. S., Jung, H. J., Kang, H., Park, G. T., Choi, Y., et al. (2014). DER containing two consecutive GTP-binding domains plays an essential role in chloroplast ribosomal RNA processing and ribosome biogenesis in higher plants. J. Exp. Bot. 65, 117-130. doi: 10.1093/jxb/ ert360

Kaczanowska, M., and Rydén-Aulin, M. (2007). Ribosome biogenesis and the translation process in Escherichia coli. Microbiol. Mol. Biol. Rev. 71, 477-494. doi: 10.1128/MMBR. 00013-07

Kim, B.-H., Malec, P., Waloszek, A., and Arnim, A. (2012). Arabidopsis BPG2: a 
phytochrome-regulated gene whose protein product binds to plastid ribosomal RNAs. Planta 236, 677-690. doi: 10.1007/s00425-012-1638-6

Kleinknecht, L., Wang, F., Stübe, R., Philippar, K., Nickelsen, J., and Bohne, A.-V. (2014) RAP, the sole octotricopeptide repeat protein in Arabidopsis, is required for chloroplast $16 S$ rRNA maturation. Plant Cell 26, 777-787. doi: 10.1105/tpc.114. 122853

Komatsu, T., Kawaide, H., Saito, C., Yamagami, A., Shimada, S., Nakazawa, M., et al. (2010). The chloroplast protein BPG2 functions in brassinosteroid-mediated post-transcriptional accumulation of chloroplast rRNA. Plant J. 61, 409-422. doi: 10.1111/j.1365-313X.2009.04077.x

Lafontaine, D. L. J., and Tollervey, D. (2001). The function and synthesis of ribosomes. Nat. Rev. Mol. Cell Biol. 2, 514-520. doi: 10.1038/35080045

Lee, K.-W., Okot-Kotber, C., LaComb, J. F., and Bogenhagen, D. F. (2013). Mitochondrial rRNA methyltransferase family members are positioned to modify nascent rRNA in foci near the mtDNA nucleoid. J. Biol. Chem. 288, 31386-31399. doi: 10.1074/jbc.M113.515692

Lesnyak, D. V., Osipiuk, J., Skarina, T., Sergiev, P. V., Bogdanov, A. A., Edwards, A., et al. (2007). Methyltransferase that modifies guanine 966 of the 16S rRNA: functional identification and tertiary structure. J. Biol. Chem. 282, 5880-5887. doi: 10.1074/jbc.M608214200

Lewis, P. J., Thaker, S. D., and Errington, J. (2000). Compartmentalization of transcription and translation in Bacillus subtilis. EMBO J. 19, 710-718. doi: 10.1093/emboj/19.4.710

Liu, H., Lau, E., Lam, M. P., Chu, H., Li, S., Huang, G., et al. (2010). OsNOA1/RIF1 is a functional homolog of AtNOA1/RIF1: implication for a highly conserved plant cGTPase essential for chloroplast function. New Phytol. 187, 83-105. doi: 10.1111/j.1469-8137.2010.03264.x

Majeran, W., Friso, G., Asakura, Y., Qu, X., Huang, M., Ponnala, L., et al. (2012). Nucleoid-enriched proteomes in developing plastids and chloroplasts from maize leaves; a new conceptual framework for nucleoid functions. Plant Physiol. 158, 156-189. doi: 10.1104/pp.111. 188474

Malagon, F. (2013). RNase III is required for localization to the nucleoid of the $5^{\prime}$ pre-rRNA leader and for optimal induction of rRNA synthesis in E. coli. RNA 19, 1200-1207. doi: 10.1261/rna.038 588.113

Melnikov, S., Ben-Shem, A., Garreau de Loubresse, N., Jenner, L., Yusupova, G., and Yusupov, M. (2012). One core, two shells: bacterial and eukaryotic ribosomes. Nat. Struct. Mol. Biol. 19, 560-567. doi: $10.1038 / \mathrm{nsmb} .2313$

Miller, O. L. Jr., Hamkalo, B. A., and Thomas, C. A. Jr. (1970). Visualization of bacterial genes in action. Science 169, 392-395. doi: 10.1126/science.169.3943.392

Nishimura, K., Ashida, H., Ogawa, T., and Yokota, A. (2010). A DEAD box protein is required for formation of a hidden break in Arabidopsis chloroplast 23 S rRNA. Plant J. 63, 766-777. doi: 10.1111/j.1365-313X.2010.04276.x

Park, Y.-J., Cho, H.-K., Jung, H., Ahn, C., Kang, H., and Pai, H.-S. (2011). PRBP plays a role in plastid ribosomal RNA maturation and chloroplast biogenesis in Nicotiana benthamiana. Planta 233, 1073-1085. doi: 10.1007/s00425-011-1362-7

Qi, Y., Armbruster, U., Schmitz-Linneweber, C., Delannoy, E., de Longevialle, A. F., Rühle, T. et al. (2012). Arabidopsis CSP41 proteins form multimeric complexes that bind and stabilize distinct plastid transcripts. J. Exp. Bot. 63, 1251-1270. doi: 10.1093/jxb/err347

Rorbach, J., and Minczuk, M. (2012). The post-transcriptional life of mammalian mitochondrial RNA. Biochem. J. 444, 357-373. doi: 10.1042/BJ20112208

Shajani, Z., Sykes, M. T., and Williamson, J. R. (2011). Assembly of bacterial ribosomes. Annu. Rev. Biochem. 80, 501-526. doi: 10.1146/annurevbiochem-062608-160432

Sharwood, R., Halpert, M., Luro, S., Schuster, G., and Stern, D. (2011). Chloroplast RNase J compensates for inefficient transcription termination by removal of antisense RNA. RNA 17, 2165-2176. doi: 10.1261/rna.028043.111

Stoppel, R., Manavski, N., Schein, A., Schuster, G., Teubner, M., Schmitz-Linneweber, C., et al. (2012). RHON1 is a novel ribonucleic acid-binding protein that supports RNase $\mathrm{E}$ function in the Arabidopsis chloroplast. Nucleic Acids Res. 40, 8593-8606. doi: 10.1093/nar/gks613

Stoppel, R., and Meurer, J. (2012). The cutting crew ribonucleases are key players in the control of plastid gene expression. J. Exp. Bot. 63, 1663-1673. doi: $10.1093 / \mathrm{jxb} / \mathrm{err} 401$

Tokuhisa, J. G., Vijayan, P., Feldmann, K. A., and Browse, J. A. (1998). Chloroplast development at low temperatures requires a homolog of DIM1, a yeast gene encoding the 18S rRNA dimethylase. Plant Cell 10, 699-712. doi: 10.1105/tpc. 10.5.699

Uchiumi, T., Ohgaki, K., Yagi, M., Aoki, Y., Sakai, A., Matsumoto, S., et al. (2010). ERALl is associated with mitochondrial ribosome and elimination of ERAL1 leads to mitochondrial dysfunction and growth retardation. Nucleic Acids Res. 38, 5554-5568. doi: 10.1093/nar/ gkq305

Walter, M., Kilian, J., and Kudla, J. (2002). PNPase activity determines the efficiency of mRNA $3^{\prime}$ end processing, the degradation of tRNA and the extent of polyadenylation in chloroplasts. EMBO J. 21, 6905-6914. doi: 10.1093/emboj/ cdf686

Yu, F., Liu, X., Alsheikh, M., Park, S., and Rodermel, S. (2008). Mutations in SUPPRESSOR OF VARIEGATION1, a factor required for normal chloroplast translation, suppress var2-mediated leaf variegation in Arabidopsis. Plant Cell Online 20, 1786-1804. doi: 10.1105/tpc.107.054965

Conflict of Interest Statement: The author declares that the research was conducted in the absence of any commercial or financial relationships that could be construed as a potential conflict of interest.

Received: 27 March 2014; accepted: 19 May 2014; published online: 05 June 2014.

Citation: Bohne A-V (2014) The nucleoid as a site of rRNA processing and ribosome assembly. Front. Plant Sci. 5:257. doi: 10.3389/fpls.2014.00257

This article was submitted to Plant Physiology, a section of the journal Frontiers in Plant Science.

Copyright (c) 2014 Bohne. This is an open-access article distributed under the terms of the Creative Commons Attribution License (CC BY). The use, distribution or reproduction in other forums is permitted, provided the original author(s) or licensor are credited and that the original publication in this journal is cited, in accordance with accepted academic practice. No use, distribution or reproduction is permitted which does not comply with these terms. 